\title{
Prevalence of Stress Urinary Incontinence in Women with Multiple Sclerosis
}

\author{
Alana M Murphy, Francois Bethoux ${ }^{1}$, Darlene Stough ${ }^{1}$, Howard B Goldman \\ Cleveland Clinic Glickman Urological Institute, ${ }^{1}$ Cleveland Clinic Neurological Institute, Cleveland, OH, USA
}

Purpose: The purpose of this study was to determine the prevalence of stress urinary incontinence (SUI) in women with multiple sclerosis (MS) and to what degree these women are bothered by their SUI, since there is a paucity of literature regarding the nature of SUI in this unique population of women.

Methods: We conducted a prospective Institutional Review Board approved study. Women scheduled for outpatient follow-up appointments at a dedicated MS center were asked to complete a questionnaire regarding urinary incontinence. Urgency urinary incontinence (UUI) and SUI were defined as an answer of slightly, moderately or greatly to the Urogenital Distress Inventory (UDI-6) question \#2 and question \#3, respectively. Impact of SUI on physical activity was determined by Incontinence Impact Questionnaire (IIQ-7) question \#2.

Results: A total of 55.9\% (80/143) women had SUI, 70.6\% (101/143) women had UUI, and 44.8\% (64/143) women had mixed urinary incontinence. The mean age was 45.8 years old (range, 20 to 72 years). Women with SUI were significantly older (mean, 47.2 vs. $41.9 ; \mathrm{P}=0.023$ ) and there was a trend towards a greater body mass index (mean, 29.3 vs. 26.5; $\mathrm{P}=0.057)$. Women with SUI had significantly higher IIQ-7 scores compared to women without SUI $(\mathrm{P}<0.001)$. Impact of urinary incontinence on physical activity was also found to be significantly greater in women with SUI (mean IIQ-7 question \#2, 0.96 vs. 0.35 ; $\mathrm{P}<0.001$ ). Conclusions: The prevalence of SUI in women with MS is $55.9 \%$ and the presence of SUI has a significant impact on their quality of life. A comprehensive urologic evaluation of a woman with MS should include assessment of SUI.

Keywords: Stress urinary incontinence; Multiple sclerosis; Prevalence; Quality of life

\section{INTRODUCTION}

Stress urinary incontinence (SUI) is defined by the International Continence Society as the involuntary leakage of urine on effort or exertion, or on sneezing or coughing [1]. SUI has a negative impact on the quality of life (QoL) of many women $[2,3]$. The estimated prevalence of SUI in the general adult female population ranges between $16 \%$ and $25 \%$, depending on the definition of SUI used and the study population [4-7]. While numerous studies have sought to determine the prevalence of SUI, few studies have focused on women with multiple sclerosis (MS). Data from the 2005 North American Research Committee on Multiple Sclerosis (NARCOMS) survey of 9,702 MS pa- tients reported responses to the Urogenital Distress Inventory (UDI-6) [8]. According to the survey, 58\% of women with MS reported some degree of urinary leakage with physical activity. This prevalence data has not been confirmed in a more contemporary cohort and there remains a paucity of data regarding the nature of SUI in women with MS.

Women with MS routinely seek urologic care. The NARCOMS survey indicated that $65 \%$ of women with MS reported at least one moderate to severe urinary symptom [8]. Despite the high prevalence of urinary symptoms in this patient population, women with MS are most likely to seek treatment for overactive bladder in the form of urinary urgency, frequency and urge urinary incontinence (UUI) [9]. Anecdotal reports
Corresponding author: Alana M Murphy

Cleveland Clinic Glickman Urological Institute, 9500 Euclid Avenue Q10-1, Cleveland, OH44195, USA

Tel: +1-216-445-1568 / Fax: +1-216-445-7031

E-mail: alana.m.murphy.md@gmail.com

Submitted: April 18,2012 / Accepted after revision: June 8, 2012
This is an Open Access article distributed under the terms of the Creative Commons Attribution Non-Commercial License (http://creativecommons.org/licenses/by-nc/3.0/) which permits unrestricted non-commercial use, distribution, and reproduction in any medium, provided the original work is properly cited. 
suggest that few women with MS present to a urologist with a complaint of SUI. The reason for this trend is unclear. One answer may be that there is a protective aspect of MS that leads to a low prevalence of SUI or SUI may be overshadowed by competing medical and urologic issues. The objective of this study was to increase the understanding of SUI in women with MS by determining the prevalence of SUI in women with MS and determining to what degree these women are bothered by their SUI.

\section{MATERIALS AND METHODS}

We conducted a prospective questionnaire based study that was approved by the Institutional Review Board. During a three month period from November to January 2011, all female adult patients at a large dedicated MS center were asked to participate in the study during their visit check-in process. We included all women willing to complete the questionnaire, regardless of the presence or absence of urologic complaints. We excluded two patients with an indwelling catheter. The study was conducted every Tuesday and Thursday over the three month period and the target female population largely consisted of a highly functional and ambulatory group. Patients willing to participate in the study were given a cover letter explaining the study's objective and a two page anonymous questionnaire. The first page of the questionnaire consisted of demographic data, parity history and a brief urologic and MS history. The second page consisted of two validated questionnaires, the UDI-6 and the Incontinence Impact Questionnaire (IIQ-7) [10]. Both the UDI-6 and the IIQ-7 questionnaires include a 4-point response scale: 1 indicating "not at all," 2 indicating "slightly," 3 indicating "moderately," and 4 indicating "greatly." UUI was defined as a response of slightly, moderately or greatly to UDI-6 question \#2: "Do you experience and, if so, how much are you bothered by urine leakage related to the feeling of urgency?" SUI was defined as a response of slightly, moderately or greatly to UDI-6 question \#3: "Do you experience and, if so, how much are you bothered by urine leakage related to physical activity, coughing or sneezing?" The impact of SUI of their physical activity was assessed by question \#2 on the IIQ-7: "Has urinary leakage affected your physical recreation such as walking, swimming or other exercise?"

Statistical analysis was performed using IBM SPSS ver. 18.0 (IBM Co., Armonk, NY, USA). All respondents were included and only those patients who did not complete the UDI- 6 and IIQ-7 questionnaires were excluded before the final analysis.
Student's t-test analysis with $\alpha=0.05$ was used to compare continuous variables with women with MS stratified by the presence or absence of SUI.

\section{RESULTS}

A total of 143 women with MS were included in the final dataset after 8 women were excluded due to unanswered UDI- 6 and IIQ-7 questionnaires. Patient characteristics are presented in Table 1 . The mean age was 45.8 years old (range, 20 to 72 years) and the mean duration of MS was 12.4 years (range, 1 to 43 years). The majority of patients (96.5\%) were under the care of a neurologist and $85.0 \%$ of the women were currently using a maintenance therapy for MS. A minority of patients (18.9\%) reported that they had lower urinary tract dysfunction before their diagnosis with MS.

A total of 80/143 (55.9\%) women had SUI, 101/143 (70.6\%) women had UUI, and 64/143 (44.8\%) women had mixed urinary incontinence (UI). No woman had undergone a previous anti-incontinence procedure. UDI-6 question \#3 allowed patients to report their level of bother as an indication of the severity of their SUI. Of the 80 women with MS and SUI, 43 (53.8\%) answered slightly, 16 (20.0\%) answered moderately and 21 (26.2\%) answered greatly (Fig. 1).

When women with SUI were compared to women without SUI, women with SUI were significantly older (mean, 47.2 vs. 41.9; $\mathrm{P}=0.023$ ) and there was a trend towards a greater body mass index (mean, 29.3 vs. 26.5; $\mathrm{P}=0.057$ ) (Table 2). There was no significant difference in the number of vaginal deliveries (mean, 1.35 vs. $1.19 ; \mathrm{P}=0.514$ ). Women with SUI had significantly higher IIQ-7 scores (mean, 6.8) compared to women without SUI (mean, 2.5; P<0.001). IIQ-7 question \#2 allowed patients to indicate how their SUI impacts their physical activi-

Table 1. Patient characteristics for women with multiple sclerosis (MS)

\begin{tabular}{ll}
\hline Characteristic & \multicolumn{1}{c}{ Value } \\
\hline Total number & 143 \\
Age $(\mathrm{yr})$ & $45.8(20-72)$ \\
Body mass index $\left(\mathrm{kg} / \mathrm{m}^{2}\right)$ & $28.5(15.5-49.3)$ \\
Parity & $1.57(0-8)$ \\
No. of vaginal deliveries & $1.29(0-8)$ \\
Duration of MS $(\mathrm{yr})$ & $12.4(1-43)$ \\
\hline
\end{tabular}

Values are presented as mean (range). 


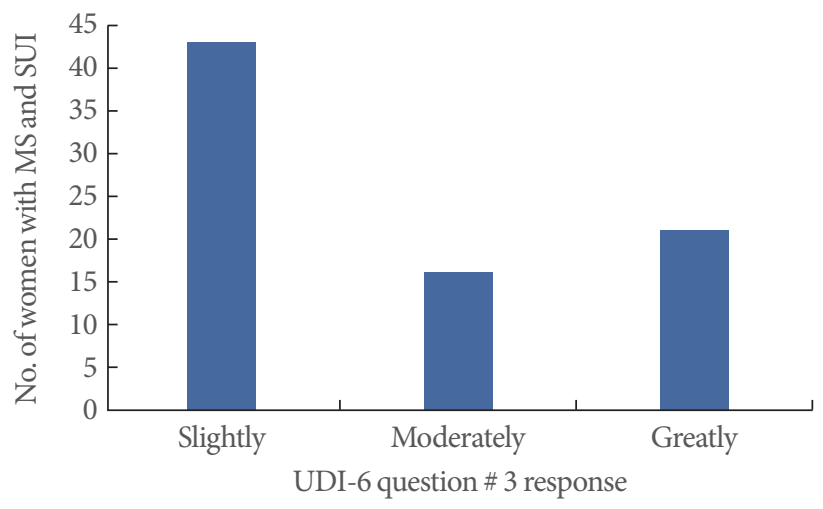

Fig. 1. Severity of stress urinary incontinence (SUI) in women with multiple sclerosis (MS) based on responses to the Urogenital Distress Inventory (UDI-6) question \#3: "Do you experience and, if so, how much are you bothered by urine leakage related to physical activity, coughing or sneezing?"

Table 2. Comparison of patient characteristics with patients stratified by presence or absence of stress urinary incontinence (SUI)

\begin{tabular}{lccc}
\hline Characteristic $\left.^{\mathrm{a}}\right)$ & $\begin{array}{c}\text { SUI } \\
(\mathrm{n}=80)\end{array}$ & $\begin{array}{c}\text { No SUI } \\
(\mathrm{n}=63)\end{array}$ & P-value \\
\hline Age $(\mathrm{yr})$ & 47.2 & 41.9 & 0.023 \\
Body mass index $\left(\mathrm{kg} / \mathrm{m}^{2}\right)$ & 29.3 & 26.5 & 0.057 \\
Parity & 1.65 & 1.48 & 0.517 \\
Vaginal deliveries & 1.35 & 1.19 & 0.514 \\
Total IIQ-7 & 6.81 & 2.48 & $<0.001$ \\
IIQ-7 question \#2 & 0.96 & 0.35 & $<0.001$ \\
\hline
\end{tabular}

IIQ, Incontinence Impact Questionnaire.

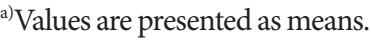

ty. Women with SUI had a significantly greater negative impact on their physical activity compared to women without SUI (mean IIQ-7 question \#2, 0.96 vs. 0.35 ; $\mathrm{P}<0.001$ ). Of the 80 women with MS and SUI, 40 (50.0\%) indicated that SUI had no impact on their physical activity, 15 (18.8\%) indicated a slight impact on their physical activity and 25 (31.2\%) indicated a moderate or great impact on their physical activity (Fig. 2).

In contrast to the large percentage of patients under the care of a neurologist, the majority of women in the study $(62.3 \%$, $89 / 143$ ) were not under the care of a urologist. Of the 117 women who reported some form of UI, only $41.0 \%$ (48/117) were under the care of a urologist. Of the 35 patients taking an anticholinergic or an alpha-blocker, $71.4 \%$ (25/35) were under the care of a urologist.

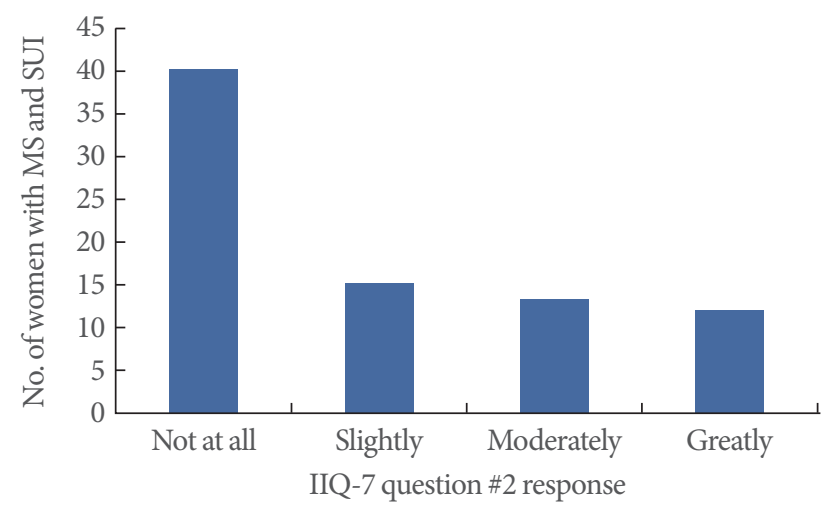

Fig. 2. Bother of stress urinary incontinence (SUI) in women with multiple sclerosis (MS) based on responses to the Incontinence Impact Questionnaire (IIQ-7) question \#2: "Has urinary leakage affected your physical recreation such as walking, swimming or other exercise?"

\section{DISCUSSION}

Despite anecdotal reports suggesting that few women with MS present to a urologist with a complaint of SUI, our prospective questionnaire based study determined that SUI is not uncommon amongst women with MS. The SUI prevalence rate of $55.9 \%(80 / 143)$ in women with MS is consistent with the 2005 NARCOMS data but greater than SUI prevalence rates estimated from general population studies [4-8]. A recent study by Markland et al. [7] analyzed data from the National Health and Nutrition Examination Survey, which defined SUI as a positive response to the question, "During the past 12 months, have you leaked or lost control of even a small amount of urine with activity like coughing, lifting or exercise?" The study reported an age standardized SUI prevalence of $25 \%$ in adult women. The higher prevalence rate in women with MS indicates that some degree of SUI is common in this unique population of women. The exact reason for a higher prevalence rate of SUI in women with MS compared to the general female population is unclear and merits further research. When women with MS and SUI were compared to women with MS and no SUI, several patterns were reflective of general population based studies. Women with SUI were significantly older and tended to be heavier, two recognized risk factors for the development of SUI [6,11].

The UDI-6 and IIQ-7 allowed patients to characterize their SUI and to indicate the degree of impact SUI has on their physical activity. When women with MS and SUI answered UDI-6 question \#3, just under half of the women (46\%) were moderately or greatly bothered by their SUI. Although just over half of 
the women (54\%) were only slightly bothered by their SUI, answers to the IIQ-7 questionnaire demonstrated that SUI has a significant negative impact on their lives. When women with MS and SUI were compared to women with MS and no SUI, the women with SUI had significantly higher overall IIQ-7 scores and IIQ-7 question \#2 scores $(\mathrm{P}<0.001)$. Nearly one third of women with MS and SUI (31\%) indicated that SUI had at least a moderate or great impact on their physical activity. Physical activity and exercise are recommended in MS patients, based on literature demonstrating that exercise improves fatigue, fitness, and QoL [12]. The negative impact of SUI adds to the activity limitations caused by other neurologic impairments, and further compromises the MS patient's ability to maintain their functional status and independence.

The high prevalence rate, the significant degree of bother and the negative impact on their lives highlights the importance of screening women with MS for SUI. If treatment of SUI is being considered, a recent United Kingdom consensus panel recommends the use of urodynamics to identify underlying lower urinary tract dysfunction [13]. Women with MS are susceptible to other forms of lower urinary tract dysfunction, such as detrusor sphincter dysnergia, and future research should examine the treatment of SUI in this patient population.

The majority of patients (59\%) with any form of UI were not under the care of urologist, which suggests that this unique patient population is underserved in terms of their urologic needs. Despite the need for more stringent evaluation of SUI in women with MS to identify coexisting lower urinary tract dysfunction, treatment options are available with the potential to improve their QoL [14]. Reasons for limited urologic care include restricted access to a urologist familiar with lower urinary tract dysfunction and inadequate patient education regarding treatments for UI. Neurologists with a MS focused practice will encounter UI in their patients and may feel well equipped to conservatively manage UI. In addition, competing medical issues may overshadow UI and leave patients with limited time and energy to address their urologic concerns.

This single institution study did have several limitations. Due to the nature of the study, there was no objective measure of SUI, no standardized functional status and the questionnaire did not assess menopausal status or ethnicity, factors known to influence the prevalence of SUI $[15,16]$. Finally, the study design is subject to a degree of selection bias since we only captured women actively seeking medical care. This selection bias may have contributed to an overestimation of the prevalence of SUI in the overall population of women with MS.

Based on the results of this questionnaire based study, the prevalence of SUI in women with MS is 55.9\% (80/143). Using a contemporary cohort of women with MS, this study supports the SUI prevalence data captured in the 2005 NARCOMS survey [8]. While just over half of women with MS and SUI indicated that they are not significantly bothered by their SUI, SUI has a significant negative impact on their QoL and nearly one third reported a significant impact on their physical activity. These women may benefit from treatment of their SUI and screening for SUI should not be overshadowed by assessment and treatment of overactive bladder.

\section{CONFLICT OF INTEREST}

Alana M Murphy, MD: none.

Francois Bethoux, MD: Allergan (speaker); Medtronic (speaker). Darlene Stough, RN MSCN: none.

Howard B Goldman, MD: Johnson \& Johnson (speaker, consultant); American Medical Systems (consultant); Pfizer (speaker, consultant); Allergan (speaker, consultant); Astellas (speaker); Teva (consultant).

\section{REFERENCES}

1. Haylen BT, de Ridder D, Freeman RM, Swift SE, Berghmans B, Lee J, et al. An International Urogynecological Association (IUGA)/International Continence Society (ICS) joint report on the terminology for female pelvic floor dysfunction. Neurourol Urodyn 2010; 29:4-20.

2. Botlero R, Bell RJ, Urquhart DM, Davis SR. Urinary incontinence is associated with lower psychological general well-being in community-dwelling women. Menopause 2010;17:332-7.

3. Kwon BE, Kim GY, Son YJ, Roh YS, You MA. Quality of life of women with urinary incontinence: a systematic literature review. Int Neurourol J 2010;14:133-8.

4. Nygaard I, Barber MD, Burgio KL, Kenton K, Meikle S, Schaffer J, et al. Prevalence of symptomatic pelvic floor disorders in US women. JAMA 2008;300:1311-6.

5. Waetjen LE, Liao S, Johnson WO, Sampselle CM, Sternfield B, Harlow SD, et al. Factors associated with prevalent and incident urinary incontinence in a cohort of midlife women: a longitudinal analysis of data: study of women's health across the nation. Am J Epidemiol 2007;165:309-18.

6. Minassian VA, Stewart WF, Wood GC. Urinary incontinence in 
women: variation in prevalence estimates and risk factors. Obstet Gynecol 2008;111(2 Pt 1):324-31.

7. Markland AD, Richter HE, Fwu CW, Eggers P, Kusek JW. Prevalence and trends of urinary incontinence in adults in the United States, 2001 to 2008. J Urol 2011;186:589-93.

8. Mahajan ST, Patel PB, Marrie RA. Under treatment of overactive bladder symptoms in patients with multiple sclerosis: an ancillary analysis of the NARCOMS Patient Registry. J Urol 2010;183:1432-7.

9. McGrother CW, Donaldson MM, Hayward T, Matthews R, Dallosso $\mathrm{HM}$, Hyde $\mathrm{C}$, et al. Urinary storage symptoms and comorbidities: a prospective population cohort study in middle-aged and older women. Age Ageing 2006;35:16-24.

10. Uebersax JS, Wyman JF, Shumaker SA, McClish DK, Fantl JA. Short forms to assess life quality and symptom distress for urinary incontinence in women: the Incontinence Impact Questionnaire and the Urogenital Distress Inventory. Continence Program for Women Research Group. Neurourol Urodyn 1995;14:131-9.

11. Hunskaar S. A systematic review of overweight and obesity as risk factors and targets for clinical intervention for urinary incontinence in women. Neurourol Urodyn 2008;27:749-57.

12. Petajan JH, Gappmaier E, White AT, Spencer MK, Mino L, Hicks RW. Impact of aerobic training on fitness and quality of life in multiple sclerosis. Ann Neurol 1996;39:432-41.

13. Fowler CJ, Panicker JN, Drake M, Harris C, Harrison SC, Kirby M, et al. A UK consensus on the management of the bladder in multiple sclerosis. J Neurol Neurosurg Psychiatry 2009;80:470-7.

14. Tennstedt SL, Litman HJ, Zimmern P, Ghetti C, Kusek JW, Nager CW, et al. Quality of life after surgery for stress incontinence. Int Urogynecol J Pelvic Floor Dysfunct 2008;19:1631-8.

15. Waetjen LE, Ye J, Feng WY, Johnson WO, Greendale GA, Sampselle $\mathrm{CM}$, et al. Association between menopausal transition stages and developing urinary incontinence. Obstet Gynecol 2009;114:989-98.

16. Fenner DE, Trowbridge ER, Patel DA, Fultz NH, Miller JM, How$\operatorname{ard} \mathrm{D}$, et al. Establishing the prevalence of incontinence study: racial differences in women's patterns of urinary incontinence. J Urol 2008;179:1455-60. 